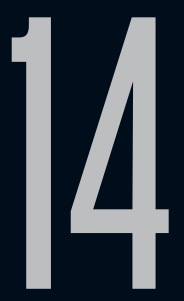

\title{
O CULTO DE CTHULHU NA CIBERCULTURA: AS RESSIGNIFICAÇÕES DO CONTO DE H.P. LOVECRAFT NO FACEBOOK
}

Gabriela Birnfeld Kurtz (UFRGS)

Recebido em 26 fev 2017. Aprovado em 12 abr 2017.
Gabriela Birnfeld Kurtz é mestra em Comunicação Social pela PUCRS, doutoranda em Comunicação e Informação na UFRGS. Professora no curso de Comunicação Social - Habilitação em Publicidade e Propaganda da PUCRS. Seu trabalho acadêmico concentra-se principalmente na cibercultura, estudos de fãs, games e violência simbólica. Lattes: http:// lattes.cnpq.br/5693956922893932. Contato: gabriela. kurtz@pucrs.br.

Resumo: O grande marco do estilo literário de horror cósmico foi atribuído à publicação do conto "O Chamado de Cthulhu", escrito por H.P. Lovecraft, na revista Weird Tales, em 1926. A narrativa não apenas influenciou outros escritores da época, como perdura até hoje na cultura pop. O deus ancestral Cthulhu, com sua cabeça tentacular, asas e garras prodigiosas, cujo nome não pode ser pronunciado por línguas humanas, ganhou um lugar de destaque na atualidade, reunindo muitos fãs. Contudo, percebe-se que há novas interpretações tanto para o conto quanto para o personagem. O objetivo do presente artigo é investigar as ressignificações e permanências existentes nos conteúdos criados por fãs acerca do conto "O Chamado de Cthulhu". A análise é fundamentada nas teorias de fãs de Henry Jenkins, 
Matt Hills e Joli Jenson, e também na classificação dos contos lovecraftianos idealizada por Sunand Tryambak Joshi. Um dos ambientes mais frutíferos para a proliferação dessas criações são os sites de Redes Sociais. Por conta disso, a análise se dá em uma página de fãs no Facebook. Por meio da realização da coleta e observação de postagens, e da criação de categorias relacionadas ao conto original, é possível compreender de que forma se dá a interpretação dos fãs.

Palavras-chave: Cibercultura; Cultura de fãs; H.P. Lovecraft; Cthulhu.

Abstract: The great milestone of the cosmic horror literary style was attributed to the publication of the tale "The Call of Cthulhu", written by H. P. Lovecraft, in Weird Tales magazine, in 1926. The narrative not only influenced other writers in that time, as it lasts up to now in pop culture. The elder god Cthulhu, with its tentacular head, prodigious wings and talons, which name cannot be pronounced by human languages, has earned pride of place in actuality, gathering many fans. However, it is perceived that there are new interpretations both for the story and for the character. The objective of the present article is to investigate the resignifications and stays existing in fan created content about the tale "The Call of Cthulhu". The analysis is substantiated in Henry Jenkins, Matt Hills and Joli Jenson's fan theories and also in Sunand Tryambak Joshi's lovecraftian's tales classification. One of the most fruitful environments for the spread of these creations are the Social Network sites. On account of this, the analysis takes place in one fan page on Facebook. Through the posts gathering and observation, and the creation of categories related to the original tale, it is possible to comprehend how the fans interpretation takes place.

Keywords: Ciberculture; Fan culture; H.P. Lovecraft; Cthulhu. 


\section{INTRODUÇÃO}

O grande marco que inaugurou o consagrado estilo literário de horror cósmico pode ser atribuído à publicação do conto "O Chamado de Cthulhu", de Howard Philips Lovecraft, em 1926, na revista Weird Tales. Com um roteiro fragmentado, uma série de descobertas e fatos estranhos leva os personagens envolvidos a entrar em contato com uma criatura ancestral, cujo nome não poderia ser pronunciado por humanos: Cthulhu. A figura do monstro se revela em um sonho de um dos personagens, Henry Anthony Wilcox, que a representa por meio de uma escultura: este tinha feições vagamente antropoides, uma cabeça com tentáculos, um grotesco corpo escamoso e asas rudimentares. Em um dos arcos da história, um inspetor descobre que há um culto a essa criatura, cujo objetivo é venerá-lo e aguardar seu despertar quando certas condições fossem cumpridas. Em outra parte da história, há a investigação de um naufrágio na Nova Zelândia, em que se confirma que alguns marinheiros haveriam passado pela morada do monstro, R'lyeh, e acidentalmente despertado Cthulhu. O único sobrevivente do acidente registrou este contato em um manuscrito que é encontrado por outro personagem, Francis Wayland Thurston, para após morrer de insanidade, efeito provocado pela criatura. O conto se encerra com o final da leitura do manuscrito e com a reflexão de Thurston, que se dá conta que é o próximo alvo: "Eu sei demais, e o culto ainda vive (LOVECRAFT, 2011, p.51)".

Lovecraft escreveu este conto enquanto residia em Nova lorque e, de acordo com Haden (2010), a inspiração surgiu de suas crises de pânico e de pesadelos que tinha com os arranha-céus da cidade 
e com a atmosfera urbana - Lovecraft nasceu e viveu a maior parte de sua vida na cidade interiorana de Providence, e não se sentia confortável em grandes centros urbanos. O conto transparece a filosofia que Lovecraft passou a perseguir nos seus últimos 10 anos de vida: quão pequenos são os seres humanos em relação aos horrores do universo.

A obra, lançada pela primeira vez nos anos 20, e sua vasta produção de mais de 100 contos e poemas não foram para o ostracismo. Suas criações marcam escritores até hoje, e estão presentes em diversas esferas do entretenimento, desde filmes de terror como "Uma Noite Alucinante" (Sam Raimi, 1981) e "Alien" (Ridley Scott, 1979), passando por desenhos animados - ScoobyDoo e South Park, e chegando à música, atraindo a predileção de bandas como Black Sabbath e Iron Maiden. Também serviu como base para muitos jogos, tanto físicos quanto virtuais, especialmente dentro do gênero de RPG.

Os monstros lovecraftianos não são mais os mesmos criados nos anos 20. Eles passam por uma nova fase, de apropriação, impulsionada pelos ambientes virtuais socializantes - os sites de Redes Sociais. No contexto da cibercultura, as estruturas de produção encontram-se diluídas, e grupos de pessoas que compartilham dos mesmos gostos - os fãs (JENKINS, 1992) - se reúnem em sites de Redes Sociais e apropriam-se de conteúdos previamente produzidos, criando novas maneiras de manifestar suas identidades e opiniões (RECUERO, 2009).

Partindo dessa premissa, o objetivo do presente artigo é investigar as ressignificações e permanências existentes nos 
conteúdos criados por fãs acerca do conto "O Chamado de Cthulhu". O ambiente escolhido para tal análise foi a página no site de Rede Social intitulada "Cthulhu"1. Foram analisadas produções imagéticas de fãs, de forma a buscar uma compreensão das mudanças que ocorreram no conto e do que permaneceu inalterado por meio dessa apropriação. Para esquematizar essa interpretação, a pesquisadora definiu categorias a priori a partir da literatura de S.T. Joshi (2008) sobre H.P. Lovecraft e de suas próprias observações acerca do conto.

\section{OS FÃS DE LOVECRAFT NOS SITES DE REDES SOCIAIS}

O termo fã, por ser utilizado de maneira muito corriqueira tanto na mídia, quanto em trabalhos acadêmicos (HILLS, 2002), pode trazer uma série de interpretações, tornando-o, por vezes, muito abrangente. Dessa forma, para o presente trabalho, se assumem algumas posições acerca do mesmo. Considera-se, então, adequado falar na definição de Jenkins, em "Textual Poachers: Television Fans and Participatory Culture" (1992). Segundo o autor, um fã aceita uma identidade que é permanentemente criticada ou subestimada por autoridades institucionais: ou seja, aceita e se orgulha de uma certa "marginalização" por conta de seus gostos. Jenson (2002) aponta que, antes dos estudos de Jenkins nos anos 90, havia pouca literatura que explorasse a atividade dos fãs como uma atividade normal, cotidiana, ou um fenômeno social.

O fã era visto como alguém fora do controle, presa fácil para forças externas e, acima de tudo, irracional. Já foi observado que a polarização entre o pesquisador e o fã maximizou a ideia da 
irracionalidade pelo fã, mas é inegável a influência dos estudos em comunicação da época nessa visão (JENSON, 2002). É esse contexto que Jenkins (1992) busca trazer ao conceituar essa identidade de fã - ao se sentirem marginalizados, esses indivíduos forjam uma aliança com uma comunidade de outras pessoas em defesa de preferências em comum, formando uma identidade coletiva. O fã existe na medida em que há um gosto em comum e uma necessidade de possuir uma identidade coletiva, e essa é a forma com a qual se perceberão esses indivíduos no presente artigo.

Um conjunto de fãs é frequentemente chamado de fandom. A palavra é originada pelo jogo de palavras entre a palavra fan (fã) e kingdom (reino), transmitindo a ideia de que o fandom é um território povoado e que pertence aos fãs (DUITS et al., 2014). De acordo com Fiske (1992), o fandom se difere da audiência em geral pois se refere a um senso de comunidade e é normalmente associado às formas culturais não aceitas pela estrutura dominante - música pop, romances, quadrinhos, estrelas de Hollywood, entre outros. Para Hills (2002), o fandom é sempre performativo, uma identidade que é reivindicada pelos fãs e executa um trabalho cultural.

Este trabalho cultural ao qual Hills (2002) se refere, tem ligação com as atividades que são praticadas pelos fãs. A partir do momento que os estudos de comunicação admitem que a audiência não é uma massa passiva, abre-se a possibilidade de pensar nesses indivíduos como capazes de produzir conteúdo acerca do que consomem. O pesquisador que inicia essa corrente de pensamento é De Certeau (1998), com o termo textual poaching ${ }^{2}$. Conforme o 
autor, os receptores interpretam o conteúdo internamente, sendo silenciosos, mas ativos. O que Jenkins (1992) adiciona ao conceito é a noção de que essa interpretação pode ser coletiva e que pode gerar resultados tangíveis, partindo para o exterior desses receptores sendo, então, um processo social. O autor traz ainda uma ressalva: ainda que todos os fãs possam produzir músicas, vídeos, imagens, etc. acerca do conteúdo, não são todos os indivíduos que realizam essa atividade de fato - ainda assim, o processo de interpretação é sempre ativo.

Enquanto a maioria dos fandoms tem sua origem observada - a partir de filmes, livros, quadrinhos, programas de televisão, entre outros -, os fãs de Lovecraft são um tanto diferentes. Não é possível centralizar esse fandom em algum programa produzido pela mídia, por exemplo. Sabe-se sua origem - na obra de H.P. Lovecraft -, mas nem todos os fãs se reúnem em torno da obra literária. É também em torno da figura do monstro Cthulhu que formam suas comunidades e criam novas narrativas. Isso traz a ideia de que o indivíduo é sempre fã de mais de uma coisa ao mesmo tempo (GROSSBERG, 1992), pois muitos adoradores do personagem esbarraram com ele por outros fandoms, como algum personagem dos quadrinhos, um desenho animado, um jogo, um seriado, entre outras manifestações da cultura e de produções da mídia.

De início, os fãs da literatura de Lovecraft normalmente se reuniam, em pequenos círculos, como no caso dos fãs que formam o The H.P. Lovecraft Historical Society, que criaram o jogo Cthulhu Lives, em 1984. Nesse jogo, os participantes eram convidados a resolver mistérios, como se esses fossem reais, 
algo comum no gênero de live-action $R P G^{3}$. Esses grupos de fãs também passaram a organizar convenções, como o H.P. Lovecraft Film Festival, criado em 1995, e que conta com edições anuais ${ }^{4}$, a CthulhuCon - também em edições anuais, mas desde $2009^{5}$-, e a maior e mais antiga convenção, a "Necronomicon", que foi criada em $1981^{6}$ e que contou com mais de 1.200 pessoas na convenção de $2013^{7}$. A grande manifestação de fãs lovecraftianos pode ser observada, contudo, no ambiente da sociedade em rede e da cibercultura. É nos espaços onde as pessoas podem construir laços sociais sem fronteiras geográficas que o fandom se potencializou numericamente.

Castells (2001) escreve que o novo capitalismo e as inovações na tecnologia da informação originaram uma configuração social diferente: a sociedade em rede. Essa ocorre no mundo todo, e é caracterizada por uma cultura de "virtualidade real construída a partir de um sistema de mídia onipresente, interligado e altamente diversificado" (CASTELLS, 2001, p.17), em que o padrão de vida está em processo de transformação. Existe mais flexibilidade e instabilidade nas estruturas de produção, expandindo o relacionamento entre o consumidor e o produtore essa flexibilidade é realizada no que se chama de ciberespaço. 3 O live-action RPG consiste em um jogo em que as pessoas se vestem de forma a parecer uma personagem, e inclusive agem como tal. É como uma contação de histórias interativa, na qual os jogadores, dentro de certas regras, vivem uma ou mais aventuras. Disponível em: http://www.bbc.co.uk/news/magazine-23877430. Acesso em 10.Nov.2014.

4 Disponível em: http://hplfilmfestival.com/portland-or. Acesso em: 10.Nov.2014.

5 Disponível em: http://hplfilmfestival.com/los-angeles-ca. Acesso em: 10.Nov.2014.

6 Disponível em: http://necronomicon2014.com/page.php?id=about. Acesso em: 10.Nov.2014.

7 Disponível em: http://articles.chicagotribune.com/2013-10-20/features/ct-prj1020-hp-lovecraft-cult-20131020_1_lovecraft-tales-h-p-lovecraft-film-festivalnecronomicon. Acesso em 10.Nov.2014. 
Segundo Lévy, este é "o espaço de comunicação aberto pela interconexão mundial dos computadores e das memórias dos computadores" (LÉVY, 1999, p.92). Além disso, segundo o autor, esse espaço é mutante e fluido. Assim, o que é realizado no ciberespaço pode ser definido como a cibercultura (LEMOS, 1996). Para Lemos, o que interessa nessa cultura não são os limites entre o real e o online, e sim, a maneira com a qual os indivíduos se valem da tecnologia como instrumento para a potencialização da comunicação.

Um exemplo da nova lógica de consumo na cibercultura é o site $E_{t s y^{8}}$, que reúne produtos feitos artesanalmente por fãs da obra Lovecraftiana. O Etsy é uma plataforma de vendas em que pessoas podem vender mercadorias únicas e exclusivas, e se diferencia de outros e-commerces por ser um centralizador desse tipo de venda. Com mais de 30 milhões de vendedores e compradores em todo o mundo, a visão da empresa é produzir uma economia justa, sustentável e movida por pessoas, e não por grandes companhias ${ }^{9}$. Os fãs de Lovecraft aproveitaram o Etsy para divulgar os seus produtos. Em uma pesquisa pela palavra-chave "Lovecraft"10, encontraram-se 3.685 itens relacionados à temática. Já pela palavra "Cthulhu", foram obtidos 4.582 resultados. Entre as produções à venda encontramse pinturas, impressões personalizadas, artigos de vestuário customizados, fantasias, bijuterias, bordados, adesivos, objetos de decoração, bonecos (como relógios e estátuas), máscaras, canecas, etc. É possível, portanto, dentro desse site, encontrar todo tipo de

8 Disponível em: https://www.etsy.com/. Acesso em: 14.Jan.2015.

9 Disponível em: http://extfiles.etsy.com/progress-report/2013-Etsy-Progress-Report. pdf?ref=progress_report_download>. Acesso em: 08.Abr.2014.

10 Dados obtidos em 23.Fev.2017. 
produto relacionado à temática com a possibilidade de ser enviado pelo correio para o mundo todo.

Um dos espaços mais frutíferos para as interações e publicações de fãs acerca da produção de Lovecraft é o Facebook. Ele se caracteriza no ciberespaço por ser um site de Rede Social. De acordo com Recuero, "os sites de redes sociais são os espaços utilizados para a expressão das redes sociais na Internet" (RECUERO, 2009, p.102). Boyd e Ellison (2007) categorizam como site de rede social o serviço que é baseado na Web e permite ao usuário construir um perfil público ou semi-público em um sistema fechado e liga a ele uma lista de outros perfis com os quais ele possui uma conexão. Esse sistema articula também a lista de conexões com outras realizadas no serviço. Recuero (2009) aponta que os SRSs não são redes sociais por si só, e sim atuam como suporte para o que as pessoas se conectarem e, assim, constituírem os laços. Logo, são sistemas, e quem realmente dá vida a ele são os usuários dentro desses sites.

De acordo com levantamento realizado pela autora deste artigo no dia 21 de fevereiro de 2017, atualmente existem mais de 100 páginas ligadas à palavra-chave Cthulhu no Facebook - na com maior audiência, que também é o ambiente sobre o qual será realizada a análise, a página homônima possui 327.639 fãs ${ }^{11}$, e a mais relevante dentre as criaturas criadas por Lovecraft. Para evidenciar este fato, foi realizado um levantamento com alguns monstros icônicos lovecraftianos no Facebook:

11 Disponível em: https://www.facebook.com/DreamingCthulhu/. Acesso em 21.Fev.2017. 


\begin{tabular}{|l|l|l|l|}
\hline Personagem & $\begin{array}{l}\text { Número de } \\
\text { páginas no } \\
\text { Facebook }\end{array}$ & $\begin{array}{l}\text { Página com mais } \\
\text { curtidas }\end{array}$ & $\begin{array}{l}\text { Número de } \\
\text { curtidas }\end{array}$ \\
\hline Nyarlathotep & 45 & "Nyarlathotep"1 & 6.006 \\
\hline Shub-Niggurath & 10 & "Shub-Niggurath"2 & 2.882 \\
\hline Yog-Sothoth & 30 & "Yog-Sothoth"3 & 9.925 \\
\hline Shoggoth & 34 & $\begin{array}{l}\text { "The Shoggoth } \\
\text { Assembly"4 }\end{array}$ & 1.712 \\
\hline
\end{tabular}

Tabela 1 - Personagens de H.P. Lovecraft e sua presença nas páginas do Facebook. Fonte: A autora (2017)

Dessa forma, o conto mais famoso de Lovecraft e o monstro ancestral Cthulhu são, evidentemente, os mais populares entre os fãs. Assim, realizadas as definições de fã e fandom, foi possível verificar que esse tipo de audiência tem sempre um gosto em comum e um senso de comunidade evidente, e tem potencial para realizar produções sobre o que consomem. Com a cibercultura e os sites de Redes Sociais, foi possível que estes indivíduos pudessem se conectar sem barreiras geográficas, e a uma velocidade sem precedentes. A profusão de produções de fãs aumenta exponencialmente, como foi demonstrado no exemplo do e-commerce Etsy e também pelo grande número de páginas criadas por fãs acerca do tema no Facebook. Antes de partir para a análise, se faz necessário explicar a origem das categorias propostas para compreender as produções dos fãs.

\section{CATEGORIAS DE ANÁLISE DO CONTO “O CHAMADO DE CTHULHU"}

Devido à vasta produção de Lovecraft - que totaliza 105 contos publicados $^{12}$-, muitas foram as tentativas, tanto de escritores

12 Disponível em: http://www.hplovecraft.com/writings/fiction/publish.aspx. Acesso em: 07.Jan.2014. 
próximos a ele, quanto de teóricos, de categorizar as publicações, seja em coletâneas, cronologias ou temáticas. De acordo com Tyson (2010), o próprio Lovecraft jocosamente classificou suas histórias tematizadas com os mitos como seu Yog-Sothothery, remetendo a Yog-Sothoth, que em seus contos era o guardião do portal que permitia que os outros seres de mundos longínquos chegassem a terra. Joshi (2008) observa ainda que, em uma ocasião, Lovecraft se referiu a sua série de contos conectados como Ciclo de Arkham.

Uma das versões de categorização mais difundidas é a do escritor August Derleth que, após a morte de Lovecraft, por meio de muitos acordos e manobras, conseguiu controle sobre os trabalhos do escritor e passou a denominar a mitologia lovecraftiana como os Mitos de Cthulhu (TYSON, 2010). Essa nomenclatura é criticada por teóricos em Lovecraft, como no caso de Tyson (2010), o qual considera que Cthulhu não é o foco central das histórias dentro desse conjunto. O estudioso, porém, observa que, mesmo que Cthulhu não seja o monstro mais importante do conjunto de mitos, ele é o mais popular entre o grande público. Para ele, o seu tamanho imenso, a aparência estranha, e a sua entrada dramática nos mitos conspiraram para esse favoritismo.

Já Joshi (2008) considera a classificação de Derleth imprecisa. Primeiramente, porque Lovecraft nunca se referiu em suas cartas a uma coletânea de contos. Ainda que a denominação de Derleth tenha sido criticada por não fazer jus à obra de Lovecraft, os mitos de Cthulhu, como classificação, são utilizados por Joshi (2008), mas atribuindo as criações de outros escritores em cima do que existe nos contos originais. Tyson (2010) observa que na fase inicial da escrita de Lovecraft não havia uma unidade ou uma pretensão de 
criar uma mitologia sólida. Ele costumava incorporar sonhos que tinha e transformá-los em histórias e, em algum ponto, passou a perceber que estava de fato criando uma mitologia. Joshi (2008) disserta sobre algumas classificações que foram feitas para os contos de Lovecraft, incluindo o fato de alguns autores nem considerarem que o escritor possuiu uma fase relacionada aos mitos. Joshi (2008), porém, discorda quando aponta que há, de fato, algo diferente entre os contos do escritor no início e no fim de sua carreira.

Assim, tanto Tyson quanto Joshi concordam com a ideia de que as criaturas tinham um papel crucial nas histórias de horror, e que Lovecraft tinha consciência da evolução de seu trabalho. Dessa forma, tratar os contos lovecraftianos sob o viés dos mitos é uma forma plausível, pois sem eles o escritor não poderia ter estabelecido seu legado (e inspirado outros a se apropriarem de seus personagens mitológicos) e criado atmosferas de horror cósmico.

Joshi (2008), ao buscar uma classificação para os contos em questão, separa as produções de Lovecraft e dos outros autores, dissociando-as. Denomina as primeiras como mitos de Lovecraft, e as segundas como mitos de Cthulhu. Dessa forma, o autor considera ser possível compreender os propósitos estéticos e filosóficos das criações de Lovecraft como uma unidade, que é diferente das narrativas que o sucederam ou que lhe foram contemporâneas. Assim, os mitos de Lovecraft não são listados explicitamente no livro de forma proposital - o autor justifica que escolheu citar os contos decisivos para análise. Joshi, no entanto, considera que as obras as quais se encaixam nessa denominação caem em quatro categorias abrangentes. É por conta da ideia de categorização das histórias com base em algumas características definidas que se considera 
que o trabalho de Joshi (2008) entra em maior sintonia com o presente artigo. Essas categorias são importantes na realização da análise das ressignificações e interpretações dos fãs, pois destacam pontos-chave nos contos clássicos.

Dentre as categorias, a primeira diz respeito a uma topografia ficcional da Nova Inglaterra. No início de sua carreira, Lovecraft escreveu contos ambientados nesse local, mas de forma generalizada. Foi a partir do conto "The Terrible Old Man", em 1920, que o escritor iniciou a criação de toda uma geografia ficcional. Criou cidades como Arkham, Kingsport, Dunwich, Innsmouth e também outras marcas topográficas, como o Rio Miskatonic (JOSHI, 2008). O autor ainda explica que, embora esses locais sejam pano de fundo de muitas histórias, eles se modificam quanto à localização e características, pois Lovecraft nunca teve a intenção de se apegar às descrições de histórias anteriores.

A segunda categoria abrange uma crescente biblioteca de livros imaginários "proibidos". Joshi (2008) destaca o "Necronomicon" como sendo o mais famoso, e também que o seu uso e dos outros livros tornaram-se frequentes não só nos contos lovecraftianos, mas também de autores do gênero na época. Já o terceiro critério é sobre a diversa coleção de "deuses" extraterrestres ou entidades. Esse é o cerne dos Mitos de Cthulhu (que são diferentes dos Mitos de Lovecraft). Na visão do estudioso, no entanto, para Lovecraft essas criaturas são símbolos, por vezes representando o desconhecido infinito do cosmo, ou as forças inexoráveis do caos e entropia, ou outras características de sua complexa filosofia.

A quarta e última categoria destacada por Joshi (2008) é a do senso de "cosmicismo". O autor destaca que não é um tema em 
si, mas sim uma espécie de termo guarda-chuva, que serve para encapsular ou agrupar todos os outros recursos de enredo. Por exemplo, a criação do mundo ficcional dentro da Nova Inglaterra não era um elemento cósmico em si, mas corroborava para a criação de uma atmosfera mais convincente - ou pelo menos era o que Lovecraft acreditava.

Há ainda um quinto elemento, que Joshi (2008) não considera fazer parte dos quatro critérios - e tampouco é restrito aos mitos de Lovecraft, mas abrange muitas obras de Lovecraft -, que é da figura do protagonista culto. Tornando-se uma constante nos mitos de Lovecraft, personagens que são muito semelhantes ao próprio autor narram ou vivem as histórias. Como Lovecraft, a maioria dos protagonistas são homens sem filiação com meios ortodoxos de aprendizado, que pesquisam fenômenos de seus próprios interesses. Então, no meio de suas buscas, percebem que há um elemento cósmico envolvido.

Logo, pode-se perceber que os mitos de Lovecraft são delimitados por Joshi (2008) com base em alguns elementos-chave, que, em confluência, geram um padrão. O ponto de partida dos mitos de Lovecraft se deu com a criação, no verão de 1926, de seu conto mais famoso: "O Chamado de Cthulhu". Esse foi o início de uma fase criativa com muitas produções tematizadas ao redor dos critérios estabelecidos por S.T. Joshi (2008). O conto em questão, conforme o autor, conta com todas as categorias presentes. Com estes pontos em mente, foi possível estabelecer seis categorias para verificar as modificações e permanências resultantes das produções de fãs. 
A primeira diz respeito à presença da narrativa original como peça central nas imagens. Buscou-se verificar se as postagens com produções dos fãs contam com elementos da narrativa original como peça central, como a topografia ficcional, os livros proibidos, as criaturas míticas, além do monstro Cthulhu em si. A segunda refere-se à imagem do monstro Cthulhu como no conto original. Observou-se se personagem conta com suas características físicas originais, e realiza atividades ligadas ao conto original, ou está em outro contexto.

A terceira categoria se assemelha à de Joshi (2008): atmosfera de cosmicismo. Verificou-se evidências da atmosfera de horror cósmico presente no conto de Lovecraft. A quarta também é diretamente influenciada pelo elemento que Joshi (2008) observa do protagonista culto. Observou-se a presença de personagens humanos do conto original. A quinta categoria busca verificar se há termos utilizados por Lovecraft em "O Chamado de Cthulhu" nas postagens. Por fim, a sexta classificação diz respeito a algo externo aos Mitos de Lovecraft: a presença de referências contemporâneas ao conto lovecraftiano.

\section{PROCEDIMENTOS METODOLÓGICOS}

Para realizar a investigação proposta, optou-se pela análise documental de algumas imagens da página Cthulhu ${ }^{13}$, no Facebook. Holsti (1969) disserta que há três situações em que o uso da análise documental é apropriado: a primeira se refere a pesquisas em que o acesso aos dados é difícil, ou que é crucial a não-obstrução no ambiente ou sujeito estudado. A segunda 13 Disponível em: https://www.facebook.com/DreamingCthulhu. Acesso em: 21.Fev. 2017. 
engloba casos em que se deseja combinar a outras técnicas de coleta, de maneira a validar ou ratificar informações. Já a terceira, que cabe no presente artigo, diz respeito ao interesse em estudar o problema, partindo da própria expressão dos sujeitos - quando a linguagem dos indivíduos é decisiva para a compreensão do problema de pesquisa. Ou seja, para que se pretenda estudar as ressignificações e as interpretações dos fãs por meio de imagens, é crucial que se obtenha a produção desses sujeitos, exatamente da forma como foi concebida. Por isso, a análise documental se encaixa como metodologia de maneira adequada.

Na visão de Phillips (1974), por exemplo, são considerados documentos "quaisquer materiais escritos que possam ser usados como fonte de informação sobre o comportamento humano" (PHILLIPS, 1974, p.187). Contudo, em sua lista de fontes de informação constam jornais, revistas, discursos, cartas, pareceres, memorandos, diários pessoais, roteiros de programa de rádio e televisão, entre outros - e não estão previstos documentos digitais. Com o avanço das pesquisas e a necessidade de contemplar os conteúdos produzidos na internet, teóricos começaram a considerar o meio online como fonte de documentos. May (2004) considera que, além de textos, há uma gama maior de materiais: "o conteúdo da mídia de massa, os romances, as peças, os mapas, os desenhos, os livros, a internet, os documentos pessoais, [...]" (2004, p.209), e inclusive adiciona as fotografias - que, mesmo tangenciando a fronteira entre a estética e o documental, podem, também, serem registros de eventos. Logo, aliando a visão de Phillips e de May, pode-se compreender que os conteúdos produzidos na internet são documentos passíveis de análise, constituindo-se de texto ou 
de imagem, podendo ser vistos como fonte de informação sobre o comportamento das pessoas.

No que tange à amostragem da análise, vale salientar que a página "Cthulhu" existe desde 16 de fevereiro de 2008, por isso conta com um número elevado de postagens, sendo necessário selecionar algumas. De forma a buscar a menor interferência na escolha das postagens, obedecendo a um método aleatório, foram escolhidas as últimas 8 imagens, diretamente relacionadas ao monstro Cthulhu, postadas até o dia 10 de dezembro de 2014 (data do início da realização da análise). Além das figuras postadas, foi observado o texto que as acompanhava, pois, muitas vezes, ele fornece mais informações acerca da postagem. É importante atentar que a página é gerenciada por um usuário do Facebook, que controla essas postagens, realizando uma curadoria de conteúdo entre o que os seguidores da página enviam e outras fontes externas. A língua predominante da página é o inglês e, quando necessário, foram realizadas traduções. Após a coleta das postagens, as mesmas foram observadas e analisadas com foco nas categorias definidas a priori, sendo numeradas da seguinte forma:

Categoria/Elemento

1) Presença da narrativa original como peça central da imagem.

2) Imagem do monstro Cthulhu como no conto original.

3) Atmosfera de cosmicismo.

4) Personagens humanos do conto original.

5) Presença de termos utilizados por Lovecraft no conto "O Chamado de Cthulhu".

6) Referências contemporâneas.

Tabela 2 - Categorias de análise das imagens.

Fonte: a autora (2017) 


\section{ANÁLISE}

As 8 postagens selecionadas foram analisadas individualmente, de forma a se obter uma visão detalhada de cada produção de fã. Cada imagem escolhida passou pelo processo de descrição e classificação dentro das categorias escolhidas pela pesquisadora. São 8 postagens, e a ordem é da mais recente para a mais antiga.

A seguinte postagem foi publicada no dia 10 de dezembro de 2014. A administradora escreve: "Lembram-se daquela Sailor Cthulhu que compartilhei há alguns meses? Acabei de encontrar uma camiseta sobre a mesma ideia. Mas dessa vez é assustadoramente fofa". Também insere no texto o link para a loja virtual que vende a peça.
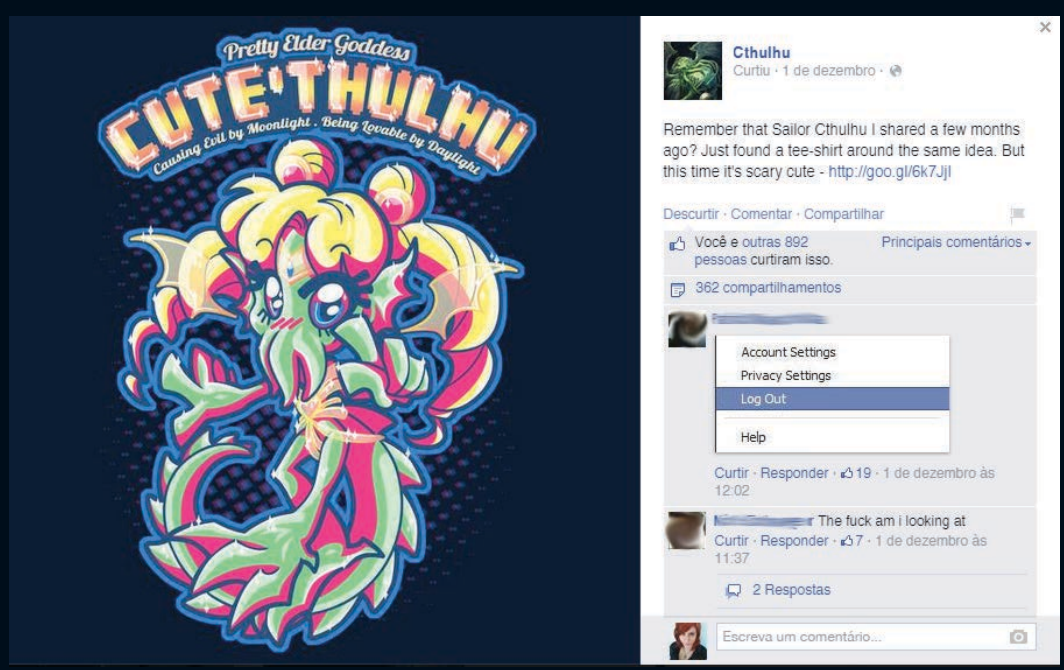

Figura 1 - Postagem 1

Fonte: Facebook. Disponível em: https://www.facebook.com/dreamingCthulhu / photos/a.10151302912462035.1073741825.10252302034/10152397889262035/?type= 1\&theater. Acesso em: 1.Dez.2014.

A imagem compartilhada trata-se de uma ilustração que une a figura do monstro Cthulhu à da personagem do animê Sailor Moon, 
que possui o mesmo nome. Na parte escrita, na primeira linha, lê-se: "Bela Deusa Antiga", o que é uma paródia direta ao nome dado à personagem da animação japonesa, que é "Bela Guardiã Sailor Moon", e à classificação dada ao monstro Cthulhu, de Deus Antigo. No título central, encontra-se a expressão "Cute'thulhu", um jogo de palavras entre cute (do inglês, fofo, adorável) e Cthulhu. Na terceira linha está escrito: "Causing evil by Moonlight. Being Lovable by Daylight ${ }^{14 "}$. Esse trecho é uma paródia direta da música de abertura ${ }^{15}$ do desenho animado: "Fighting evil by moonlight/ Winning love by daylight ${ }^{16 \prime \prime}$. A personagem ilustrada também lembra muito a original, principalmente os cabelos e o estilo de desenho, mas com elementos do monstro Cthulhu, como a cor verde, os tentáculos faciais, asas, rabo e garras.

A ilustração postada na página Cthulhu realiza uma fusão entre o monstro e a personagem Sailor Moon, unindo características de cada um, mas tornando toda a imagem mais "adorável". Logo, de acordo com as categorias, percebe-se que: 1) a narrativa não é o foco da ilustração, pois trata de uma fusão entre personagens, não havendo elementos diretamente relacionados à história; 2) a imagem do monstro, ainda que contenha elementos originais, de forma que seja reconhecível como o tal, é muito modificada, já que traz elementos do mangá e do animê. Os olhos grandes, as cores vibrantes, a presença de brilho, e a definição do gênero feminino para o personagem (nos contos de Lovecraft Cthulhu não têm gênero definido) explicitam as características que retiram a aura de medo

14 "Causando o mal sob a luz da lua. Sendo amável à luz do dia". Tradução nossa.

15 Disponível em: http://www.metrolyrics.com/sailor-moon-theme-lyrics-sailor-moon. html. Acesso em: 2.Dez.2014.

16 "Lutando contra o mal sob a luz da lua. Ganhando amor à luz do dia". Tradução nossa. 
do monstro e passam a ter um tom de paródia, e traços de "fofura"; 3) a atmosfera de horror cósmico se subtrai completamente, por conta do tom da ilustração, conforme descrito no item anterior; 4) não há presença dos personagens humanos do conto original; 5) quanto ao uso do vocabulário presente no conto, há as referências às palavras "Elder God", mas de forma parodiada, transformandose em "Pretty Elder Godess" - novamente atribuindo-se o gênero feminino, e adicionando a palavra "Pretty", oriunda do desenho animado, e 6) em relação ao uso de elementos contemporâneos externos, percebe-se a importância da personagem Sailor Moon, haja vista que toda a paródia é relacionada à ela e ao animê são utilizados elementos exclusivos do desenho animado, como a música de abertura.

A segunda postagem também é um compartilhamento de uma loja de camisetas, mas, neste caso, com a temática de natal. Compartilhada no dia 30 de novembro, trata-se de uma estampa semelhante àquelas tradicionais, bordadas em suéteres no Natal, mas com a imagem do monstro Cthulhu. A administradora convida os fãs a votarem na camiseta pelo site, para que ela se torne comercializável: "Tenha você mesmo um feliz pequeno Nathulhu $^{17}$ - VOTE se você quer ver isso impresso em uma camiseta antes dos feriados!". 


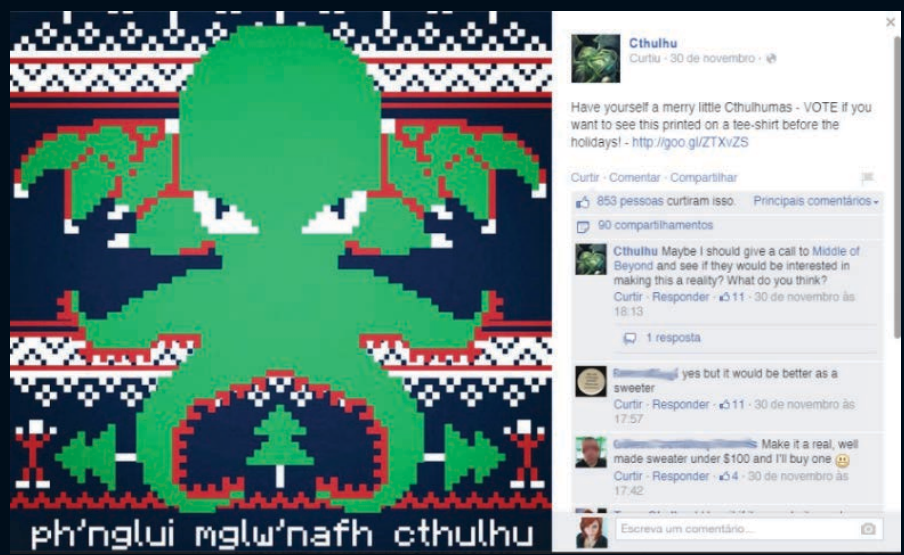

Figura 2 - Postagem 2

Fonte: Facebook. Disponível em https://www.facebook.com/dreamingCthulhu / photos/a.10151302912462035.1073741825.10252302034/10152397672572035/?type= 1\&theater. Acesso em: 1.Dez.2014.

Quanto à imagem em si e sua relação com as categorias, percebese que: 1) a narrativa do conto não é o ponto central da imagem, ainda que se utilize uma frase presente no conto; 2) o monstro Cthulhu preserva suas características do conto, mas também está mesclado à temática de Natal, emulando o bordado de um suéter tradicional dessa data, haja vista o uso de cores natalinas e de pinheiros. Além disso, é possível dizer que a imagem do personagem se tornou menos ameaçadora do que aquela descrita no conto de Lovecraft, assemelhando-se a algo "fofo", ainda que em um estilo diferente da primeira postagem; 3) a atmosfera de horror cósmico não se encontra na imagem, remetendo ao Natal; 4) não há a presença de personagens humanos do conto original. Ainda que sejam retratadas figuras humanoides, não existe referência suficiente, para que se diga que são personagens dos contos; 5) em relação aos termos do conto original, é possível ver uma parte da frase "ph'nglui mglw'nafh cthulhu R'lyeh wgah'nagl fhtagn", presente na história. 
Em "O Chamado de Cthulhu", essa frase era pronunciada por cultistas, encontrados ao redor do mundo, conforme investigação do Inspetor Legrasse, e significava "Na casa dele, em R'lyeh, repousa em sonhos o Cthulhu adormecido". Essa frase, emblemática no conto, tornou-se também muito representativa no que diz respeito ao uso que os fãs fazem dela, transformando-a praticamente em um mantra. Por conta disso, é comum que essa passagem se encontre nas manifestações criadas pelos fãs, e 6) em relação ao uso de outros elementos fora das criações de Lovecraft, há a utilização de elementos natalinos. O fã que criou a arte também se inspirou em suéteres de natal tipicamente estadunidenses, apelidados de "ugly Christmas sweaters".

O "ugly Christmas sweater", ou "suéter feio de Natal", foi popularizado nos anos 80 pelo seriado The Cosby Show, no qual os atores sempre utilizavam suéteres com estampas chamativas e inusitadas, e também por Chevy Chase, no filme Férias Frustradas, do diretor Harold Ramis, lançado em 1983. Nos anos 90, sua popularidade decaiu, mas na última década ele se tornou um artigo de moda retrô, utilizado por pessoas interessadas na moda e por celebridades ${ }^{18}$. Logo, a imagem postada demonstra essa sintonia do monstro Cthulhu com a moda, pois ele é transformado em uma estampa de camiseta inspirada nesse tipo específico de suéter.

A postagem a seguir foi publicada no dia 29 de novembro de 2014. A administradora compartilha uma foto de um fã fantasiado na temática do monstro Cthulhu, unindo isso ao estilo 
steampunk. Escreve: "Cthulhu Steampunk Elegante, alguém?". Também posta o link com a referência de onde encontrou a foto, no site DeviantArt ${ }^{19}$.

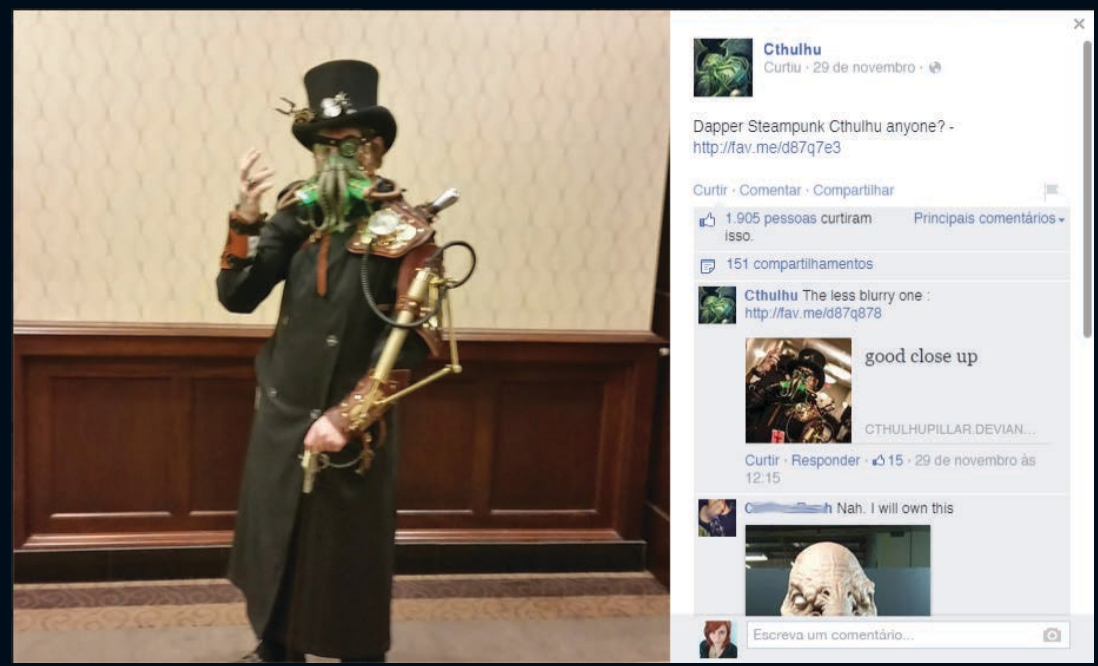

Figura 3 - Postagem 3

Fonte: Facebook. Disponível em: https://www.facebook.com/dreamingCthulhu / photos/a.10151302912462035.1073741825.10252302034/10152394955812035/?type= 1\&theater. Acesso em: 1.Dez.2014.

O steampunk, que pode ser classificado como um estilo, um subgênero, ou uma subcultura oriunda da ficção científica, tem origens em escritores como Julio Verne e o próprio Lovecraft. Contudo, foi apenas nos anos 80 que o estilo foi finalmente consagrado como tal, por escritores como Jim Powers, K.W. Jeter (com o crédito de cunhar o termo steampunk), e James Blaylock, cujos livros imaginavam um mundo alternativo, inspirado na era vitoriana. Já nos anos 90, o livro The Difference Engine, de William Gibson e Bruce Sterling, consagra o gênero ao retratar o século 19 e a criação dos computadores mecânicos. O conceito evoluiu 19 Disponível em: http://cthulhupillar.deviantart.com/art/my-full-outfit-as-ProfessorWheatley-496709355. Acesso em: 6.Dez. 2014. 
para além da literatura quando aficionados em artesanato, designers de moda, e escultores passaram a criar elementos relacionados, como relógios de bolso, chapéus, e outros artigos de vestuário e decoração repletos de engrenagens e elementos da engenharia mecânica.

Relacionando a imagem às categorias definidas, podese perceber algumas diferenças dessa para as duas postagens anteriores. 1) A narrativa não é o foco central dessa criação, haja vista que se utilizam apenas os elementos visuais relacionados ao monstro, e não há menção à história; 2) a imagem do monstro é modificada, mas diferentemente das postagens anteriores, não existem aspectos "fofinhos". O que há é a mistura com o estilo steampunk, no qual o artista utiliza elementos para compor uma fantasia original, adicionando os tentáculos faciais da personagem Cthulhu a um braço mecânico, uma cartola estilizada com engrenagens, óculos, e alguns relógios, bem como uma vestimenta inspirada na era vitoriana; 3) não há mais a atmosfera de horror cósmico, haja vista que as próprias criações ligadas ao steampunk relacionam-se mais diretamente ao gênero de ficção científica; 4) em relação à presença de personagens humanos do conto original, não existe nenhuma menção. Pode-se perceber que a figura criada pelo fã é de um humano com algumas deformidades, mas não é possível dizer que se trata de uma criação diretamente oriunda do conto original, pois não há correspondências diretas como essa imagem; 5) como não há nada escrito na imagem, conclui-se que não há uso do vocabulário do conto, e 6) em relação aos elementos contemporâneos, é possível perceber o uso do estilo steampunk, popularizado entre os anos 80 e 90. Lovecraft tangenciou esse 
estilo ao aproximar a ficção científica de seus trabalhos, como em "Sussurros na escuridão", em que o autor fala de uma raça antiga que desenvolveu uma tecnologia para manter o cérebro ativo em um jarro, sendo capaz de viajar entre os planetas no alémtúmulo. Contudo, em "O Chamado de Cthulhu", o elemento de ficção científica não aparece de forma proeminente, sendo possível dizer que essa postagem também se relaciona a outras obras lovecraftianas como um todo.

A postagem a seguir foi compartilhada no dia 20 de novembro de 2014, e trata de um link direcionado a uma loja virtual, e o produto é um boton, no qual se vê escrito "Vote Cthulhu. Por que escolher o menos perverso?" A administradora também adiciona uma pergunta na postagem: "Prontos para 2016?". Assim, esta postagem relaciona-se às eleições presidenciais nos Estados Unidos, que ocorreram em 2016.

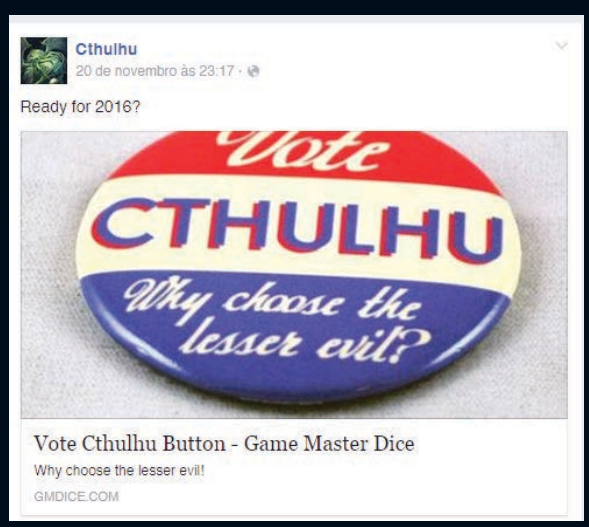

Figura 4 - Postagem 4

Fonte: Facebook. Disponível em: https://www.facebook.com/dreamingCthulhu / posts/10152379745917035. Acesso em: 1.Dez.2014.

Pode-se notar que há uma forma satírica de lidar com as eleições, também trazendo um tom de crítica aos candidatos e ao 
sistema democrático. O uso da figura do monstro Cthulhu como um candidato que é perversamente honesto funciona tanto como uma manifestação de humor quanto de uma crítica. Assim, referindose às categorias, percebe-se que, mesmo não sendo um desenho ou uma fotografia, traz algumas observações interessantes. 1) Em relação à narrativa, não há menção sobre ela no boton, e apenas o nome do monstro Cthulhu é utilizado. Pode-se perceber, no entanto, que há o uso da palavra "perverso", dando a entender que o personagem é mau, o que não é exatamente o que aponta Lovecraft em seu conto, pois define Cthulhu como uma criatura que não conhece o bem e o mal, apenas o caos e sua insurgência no mundo atual traria justamente isso. Logo, essa expressão demonstra uma simplificação do papel do monstro em relação ao conto original; 2) como o boton é uma paródia dos produtos distribuídos nas eleições, ele não traz a imagem do monstro, muito menos a cor verde que tradicionalmente é utilizada pelos fãs em suas criações. As referências de cores relacionam-se diretamente àquelas utilizadas pelos dois partidos dos EUA, vermelho, branco e azul, as mesmas da bandeira do país; 3) há a diluição da atmosfera de horror cósmico, que não é evidente nesse boton; 4) bem como as outras imagens analisadas, não há presença de personagens humanos do conto original. A menção que é feita é apenas ao monstro Cthulhu; 5) não são utilizados termos do conto original, e 6) em relação aos elementos contemporâneos, pode-se perceber a sátira realizada acerca das eleições, colocando o personagem como candidato plausível para o governo dos Estados Unidos, e utilizando uma comunicação visual semelhante àquela usada nas campanhas eleitorais, como pode ser visto na imagem a seguir: 


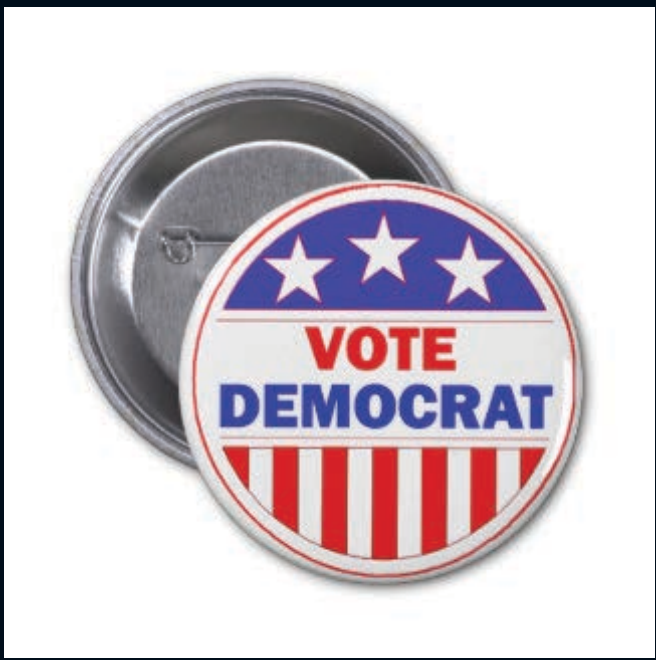

Figura 5 - Boton da campanha dos Democratas

Fonte: Zazzle. Disponível em: http://www.zazzle.com.br/democrat+bot\%C3\%B5es. Acesso em: 6.Dez.2014.

Percebe-se a semelhança muito próxima entre a imagem analisada e a comunicação visual das campanhas eleitorais estadunidenses. Comparando com a imagem da postagem original, nota-se que há uma apropriação direta desse estilo.

A quinta postagem foi publicada no dia 17 de novembro de 2014, e trata-se de um compartilhamento realizado pela administradora a partir de um site de tirinhas, Optipess ${ }^{20}$. Na descrição: "Será que eles poderiam fazer um telefone do tamanho de uma tela IMAX? Ou duas, para que se esteja do lado seguro". Nesse caso, a administradora fala como se fosse o monstro Cthulhu: 


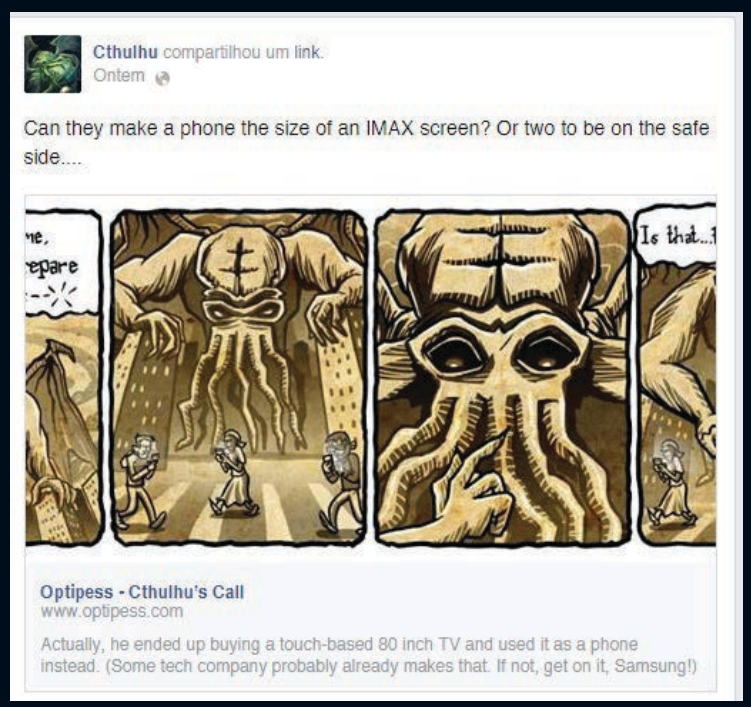

Figura 6 - Postagem 5

Fonte: Facebook. Disponível em: https://www.facebook.com/dreamingCthulhu / posts/10152372928032035. Acesso em: 1.Dez.2014.

A tirinha apresenta o monstro Cthulhu prestes a atacar humanos em uma cidade contemporânea. No primeiro quadro, ele diz: "Tremam diante de mim, humanos insignificantes! Preparemse para o eterno torme...". No segundo, o personagem olha para os humanos e todos estão olhando para os seus smartphones. No terceiro, Cthulhu aparece, refletindo sobre isso, e no último pergunta a uma das pessoas: "Isso é... o novo iDroid Lumia?". Podese perceber que a aparência do personagem, que nos primeiros quadros parece ser semelhante à descrita por Lovecraft no conto, abranda-se nos últimos dois quadros, em que é retirada de seu semblante a maldade, demonstrando que ele não representaria mais perigo algum.

Assim, relacionando a imagem às categorias, observa-se que: 1) A narrativa original não é o foco central da tirinha, pois se trata 
de uma continuação, em que Cthulhu acorda nos tempos atuais, se depara com as tecnologias existentes, e se interessa por elas; 2) a imagem do monstro inicialmente corresponde ao descrito no conto, mas sua expressão se modifica no meio da tirinha, tornandose mais amena. Cthulhu é retratado realizando uma atividade do conto, ao acordar de seu sono eterno e tentar destruir a cidade, mas isso logo é desconstruído quando ele se interessa pelo smartphone; 3) a atmosfera de horror cósmico se dilui, haja vista que o tema da imagem é humorístico, e busca justamente trazer a inversão dos estilos; 4) não há a presença de personagens humanos do conto original; 5) não são utilizados termos do conto original, tendo em vista que o personagem Cthulhu não fala nenhuma língua humana, e que a linguagem é transportada para os dias atuais, e 6) em relação às referências a elementos contemporâneos, é possível perceber a referência aos smartphones mais populares no mercado, como o iPhone, o Nokia Lumia, e ao sistema operacional mobile Android Cthulhu pergunta ao humano se o modelo é "iDroid Lumia". Assim, o personagem se encontra descontextualizado, transportado aos dias atuais em plena era da informação. O intuito é modificar a imagem do mesmo ao focar no humor e na humanização do personagem, pois ele, tal como os mortais, também se interessa por smartphones e tecnologia, a ponto de desistir de seu propósito (destruir a humanidade) por um instante.

A sexta postagem foi compartilhada pela administradora no dia 16 de novembro de 2014, e se trata do compartilhamento de uma fotografia tirada por um fã e postada no site DeviantART. A Administradora escreve: "Eu acho que a Polônia precisa de mim! Vote nos Deuses Antigos pelo deviantartist KingOvRats". 

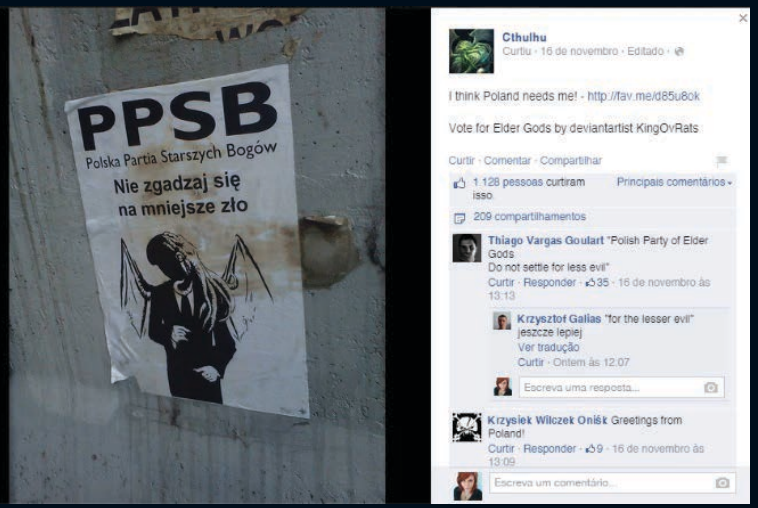

Figura 7 - Postagem 6

Fonte: Facebook. Disponível em: https://www.facebook.com/dreamingCthulhu / photos/a.10151302912462035.1073741825.10252302034/10152372247197035/?type= 1\&theater. Acesso em: 1.Dez.2014.

Sobre as categorias, percebem-se algumas diferenças em relação à forma com a qual a imagem da postagem 4, que também trata de eleições, é composta. 1) Em relação à narrativa original, mantêm-se a mesma ideia da imagem 4, em que há essa ideia de que o monstro Cthulhu é mau, perverso; 2) a imagem do personagem Cthulhu aparece, mas com algumas modificações. Ainda que não traga traços "fofos", como nas análises anteriores, o monstro aparenta bastante antropomorfizado, com mãos humanas, e, inclusive, vestindo terno. Contudo, seu rosto e suas asas evidenciam as características mais marcantes do monstro, havendo ainda um pouco da descrição do conto original; 3) a atmosfera de horror cósmico dá lugar ao tom satírico em relação às eleições, sendo diluída; 4) apesar de o monstro Cthulhu ser retratado como um ser metade humano metade polvo com asas, não há menção alguma aos personagens humanos do conto lovecraftiano; 5) quanto ao uso de expressões vindas do conto original, percebe-se a presença do uso da expressão "Deuses Antigos", que é utilizada por Lovecraft. 
Isso já demonstra certo conhecimento acerca da obra, ainda que o uso da palavra perverso seja um tanto impreciso, e 6) quanto ao uso de elementos contemporâneos, pode-se perceber a forma com a qual o monstro é retratado - com um terno -, demonstrando que a imagem é bem atual. Além disso, a própria temática das eleições traz uma ideia atual, assim como aquela retratada na postagem 4.

A sétima postagem foi realizada no dia 14 de novembro de 2014, e não há nenhum enunciado escrito pela dona da página. Na imagem, lê-se, em branco: “Agradeça Cthulhu, é sexta-feira!" e, abaixo, no balão: "Por que não Zoidberg?".

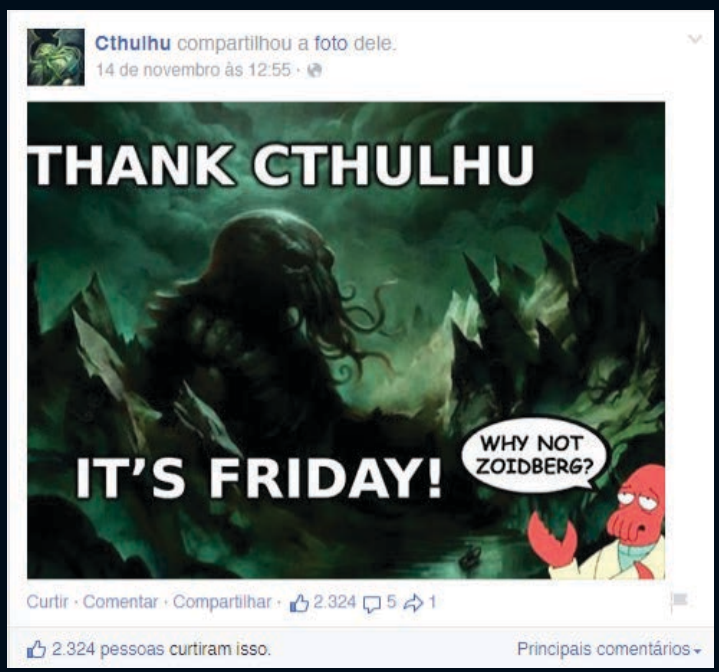

Figura 8 - Postagem 7

Fonte: Facebook. Disponível em: https://www.facebook.com/dreamingCthulhu / posts/10152369219252035. Acesso em: 6.Dez.2014.

Essa imagem é a união de dois memes $^{21}$ diferentes. O primeiro é relacionado à sexta-feira. A expressão, "Thank God it's Friday",

21 Blackmore (1999) define o meme como instruções para dar direção a um comportamento, armazenado em cérebros (ou outros objetos) e reproduzidos por imitação. 
comumente utilizada na língua inglesa, popularizou-se com o filme homônimo, lançado em 1978, e contava com Donna Summer e Jeff Goldblum ${ }^{22}$. Também abreviada para TGIF, expressão que demonstra alívio por que a semana está acabando, e que a sexta chegou, para que a pessoa possa descansar ou se divertir. A partir disso, na era da cibercultura e dos SRSs, começaram a surgir variações, inserindo não apenas Deus, mas qualquer personagem, criatura, pessoa famosa que se possa imaginar.

Já o segundo meme que está sobreposto na imagem trata-se do uso do personagem Zoidberg, da série animada Futurama (Matt Groening, 1999) e do meme chamado "Why not Zoidberg" (Por que não Zoidberg). A origem da frase, de acordo com o site Quickmeme ${ }^{23}$, remete a quando um usuário postou a imagem do personagem e a frase: "You call that an ink defense? Blughidihlgidgldgdd..." (Você chama isso de defesa de tinta? Blughidihlgidgldgdd...). No mesmo dia, uma pessoa criou uma postagem no site de Rede Social Reddit com a seguinte imagem, postada por outro usuário na página Quickmeme:

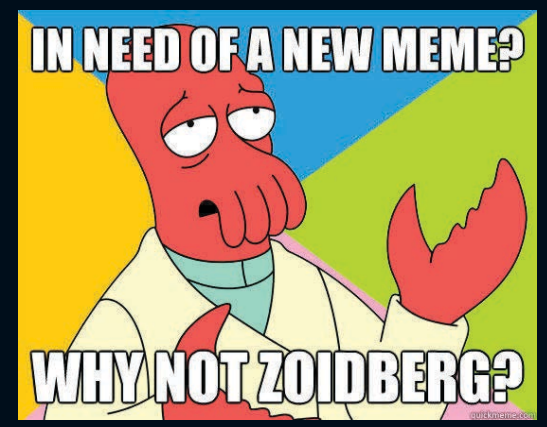

Figura 9 - Origem do meme Zoidberg

Fonte: Know Your Meme. Disponível em: http://knowyourmeme.com/memes/ futurama-zoidberg-why-not-zoidberg\#fn3. Acesso em: 7.Dez.2014. 
De acordo com as categorias, é possível perceber algumas características únicas nessa imagem. 1) Em relação ao uso da narrativa como ponto central da imagem, ela não é evidente, haja vista que a situação demonstrada utiliza o nome e a figura do monstro Cthulhu como uma variação da expressão "Thank God it's Friday". Há, no entanto, a presença de R'lyeh na imagem, a cidade submersa onde Cthulhu dorme, e também um barco, referências claras à narrativa original; 2) a imagem do personagem aparece muito semelhante àquela descrita por Lovecraft, com o mesmo aparentando ser assustador. $\mathrm{O}$ uso das cores também remete a essa atmosfera. Contudo, o mesmo deixa de ser ameaçador com a inserção da legenda, agradecendo ao monstro por ser sexta-feira, e também pela sobreposição de Zoidberg, tornando a imagem cômica; 3) o clima de horror cósmico torna-se completamente inexistente, dando lugar ao humor; 4) também não há menções a nenhum personagem humano idealizado por Lovecraft em seu conto; 5) quanto ao uso de expressões oriundas do conto original, não foi possível detectar a existência das mesmas, pois o enunciado na imagem e a fala de Zoidberg são atuais, e referenciam outros memes, e 6) em relação ao uso de elementos contemporâneos, esse é um dos exemplos mais ricos, pois a imagem não apenas referencia um meme, mas dois ao mesmo tempo. O uso desses elementos demonstra principalmente o potencial de modificação existente na figura do monstro Cthulhu, sendo possível misturá-lo com manifestações extremamente diversas da Internet.

A última postagem a ser analisada foi publicada no dia 12 de novembro de 2014, e trata-se de um compartilhamento a partir da página H.P. Lovecraft, também no Facebook. Essa postagem se difere 
das demais apresentadas na análise justamente por não contar com outros elementos além do monstro. Além disso, na descrição da foto original, consta o primeiro e uma parte do segundo capítulo do conto "O Chamado de Cthulhu".

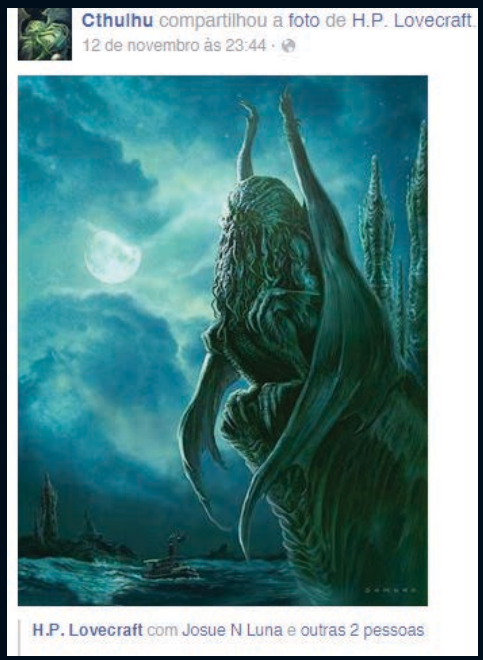

Figura 10 - Postagem 8

Fonte: Facebook. Disponível em: https://www.facebook.com/dreamingCthulhu / posts/10152366677277035. Acesso em: 1.Dez.2014.

Essa postagem, diferente das outras analisadas, conta com um trecho extenso do conto original, e com uma imagem que em muito se assemelha às descrições existentes no conto de Lovecraft. Essa, aliás, é a que mais se aproxima da obra original, e, também, diferentemente das postagens anteriores, não conta com nenhuma referência externa à história. A ilustração, devidamente creditada na postagem original, conta com o monstro Cthulhu sentado em uma pedra com ângulos estranhos, semelhante à cidade de R'lyeh. Há também um céu com lua cheia, para conferir o ar soturno, os mares agitados, e um barco. 
Em relação às categorias, essa é a imagem que mais contém elementos originais. 1) Pode-se perceber que o monstro Cthulhu é o foco principal da imagem, mas há muitos elementos presentes na narrativa original, como a cidade de R'lyeh, o navio Emma, o mar revolto - semelhante à noite em que os marinheiros acordaram Cthulhu - e a atmosfera soturna. Logo, a imagem corresponde à narrativa e tem a mesma como foco central; 2) a imagem do personagem é muito semelhante àquela descrita por Lovecraft, e não há menções de humor ou traços caricatos. Cthulhu também se apresenta sentado na pedra quase da mesma forma como foi descrito no conto, ao ser encontrada a estatueta antiga. Considerase que essa é a imagem mais próxima àquela imaginada por Lovecraft dentre as analisadas neste artigo; 3) há uma evidente atmosfera de horror dentro da imagem, por conta de elementos como a lua cheia, a névoa, e o uso das cores frias, entre o azul, o verde, e o preto. Não se pode dizer que é o horror cósmico descrito por Lovecraft, no qual se baseia principalmente no "não-mostrar" os monstros, e criar a atmosfera de desconhecimento da humanidade perante criaturas poderosas, mas essa é a que mais se aproxima do que pode ser chamado de horror em si; 4) apesar de existir a figura do barco na imagem, não há menção alguma aos personagens humanos, apenas na descrição da mesma, por ser um trecho do conto; 5) quanto ao uso de palavras existentes no conto, não há nada escrito na ilustração e, por conta disso, essa característica é inexistente, e 6) diferentemente de todas as imagens analisadas, não há referências a elementos contemporâneos e externos ao conto.

Assim, essa postagem se mostra extremamente relevante no sentido de demonstrar que, mesmo que o monstro Cthulhu 
esteja sendo modificado ativamente pela comunidade de fãs em diversos sentidos e de formas muito distintas, ainda há espaço para as produções que são de fato fiéis ao conto. O fã que criou essa ilustração demonstra um conhecimento aprofundado do conto, algo que não é tão fácil de inferir nas outras imagens apresentadas.

Ao final das descrições individuais das imagens, foi confeccionada uma tabela, de forma a tornar mais visível o processo de ressignificação do monstro Cthulhu. Para tornar a visualização mais fácil, foram escolhidas as cores vermelho para "não", amarelo para "em parte", e verde para "sim".
Categoria/Postagem
1) Presença da narrativa original como peça central da imagem
2) Imagem do monstro Cthulhu como no conto original
3) Atmosfera de cosmicismo
4) Personagens humanos do conto original
5) Presença de termos utilizados por Lovecraft no conto "O Chamado de Cthulhu"
6) Referências contemporâneas

\begin{tabular}{l|l|l|l|l|l|l|l}
1 & 2 & 3 & 4 & 5 & 6 & 7 & 8
\end{tabular}

Tabela 3 - Resumo: categorias e postagens
Fonte: Tabela confeccionada pela autora.

De acordo com essa tabela resumida, é possível perceber pontos em comum e pontos diferentes em todas as postagens. Em relação ao item 1, que corresponde à presença da narrativa original como peça central da imagem, pode-se observar que a maioria das postagens contam com temáticas centrais diferentes da narrativa. Seja retratando o monstro Cthulhu como uma personagem feminina de animê (postagem 1), transformando a imagem do mesmo em uma estampa de suéter feio de Natal (postagem 2), em personagem 
steampunk (postagem 3), em candidato político (postagens 4 e 6), ou em um aficionado por tecnologias (postagem 5), há sempre uma recriação narrativa por parte dos fãs. 0 monstro encontra-se em situações muito diferentes daquela prevista por Lovecraft no conto. Na postagem 7, classificou-se como uma presença em parte, pois na imagem de fundo há diversos elementos da narrativa. Contudo, são inseridos memes junto com a ilustração, considerando que a história original coexiste com novos elementos. Já na postagem 8, os elementos narrativos são o foco central, de modo que essa é a imagem menos alterada pelo fã que a criou.

Em relação à imagem do monstro Cthulhu, na maior parte dos casos ela se encontra muito modificada, mas não se pode dizer que está completamente diferente, pois, se estivesse, não seria possível reconhecer a criatura. Logo, é necessário que apareçam alguns elementos-chave para que os fãs reconheçam que é o personagem. Assim, a cabeça cefalópode, as asas, as garras, a figura levemente humanoide, são marcas recorrentes nessas ressignificações. Em alguns casos, a figura do monstro é de um ser inofensivo, "fofo", como no caso da postagem 1, por exemplo. Em todos esses casos, o caráter ameaçador e aterrorizante é diluído, tornando o monstro mais carismático e próximo das pessoas. As exceções encontram-se na postagem 4, principalmente porque não há nenhuma ilustração do monstro de fato; e na postagem 8, na qual o monstro é retratado de forma muito fidedigna à descrição existente no conto original.

Sobre a atmosfera de cosmicismo que existe nos contos, essa noção de que a humanidade é muito pequena em relação aos mistérios e à vastidão do universo, essa se encontra inexistente nas postagens de 1 a 7. Isso porque o monstro encontra-se em contextos diferentes, 
em que muitas vezes se explora o humor, a ironia, e inclusive uma visão crítica acerca de temas políticos. Logo, pode-se notar que esse clima apenas aparece na imagem 8, com o uso de cores e da fidelidade à narrativa original. É também possível notar que em todas as imagens não há a presença dos personagens humanos do conto de Lovecraft. Considera-se que, apesar de esses humanos serem protagonistas nas histórias, acabam por representar fortemente a marca de uma época e de uma ideologia elitista. Os elementos que ficaram foram justamente os que são atemporais, como a figura de um monstro que representa o caos e o fim da humanidade.

No que diz respeito aos termos do conto original sendo utilizados nas criações de fãs, há uma variedade. A primeira postagem brinca com os termos da história, se adaptando e se misturando com aqueles existentes no animê Sailor Moon. Já as postagens 2 e 6 contam com termos oriundos das histórias como eram escritos, mas em outros contextos. O primeiro como estampa de uma camiseta no estilo de suéter de natal, e o segundo dentro de um contexto político, no qual é criado o "Partido Polonês dos Deuses Antigos". Em outras imagens, ou por não haver texto ou pela linguagem ser muito atual, não há esse uso.

A questão das referências contemporâneas é quase unânime nas postagens. Como dissertado no primeiro capítulo, as obras de Lovecraft influenciaram largamente autores de sua época, e continuam a influenciar escritores contemporâneos. Essas também foram decisivas na criação de músicas, seriados, histórias em quadrinhos, desenhos animados, e outros produtos da cultura pop. Por conta disso, é tradicional esse uso dos "Deuses Antigos", também se misturando com os elementos atuais. 
Outro ponto interessante é o fato de a administradora da página postar constantemente produções de fãs - e algumas à venda em sites voltados para produtos exclusivamente feitos por fãs. Seja por pesquisa própria ou por meio de envio de sugestões, há esta preocupação: ao mesmo tempo trazer novidades e auxiliar os outros fãs a tornarem suas criações mais conhecidas e, por vezes, fazer com que essas sejam vendidas. É uma forma de cooperação entre os indivíduos de um mesmo fandom, na qual a administradora busca fontes externas ao SRS e centraliza em sua página, para que atinja o grupo que segue a mesma.

\section{CONSIDERAÇÕES FINAIS}

O conto que surgiu nos anos 20 a partir de perturbadores pesadelos de um escritor dos Estados Unidos não é mais o mesmo. Por meio da análise e observação da produção de fãs, foi possível encontrar diversas mudanças em "O Chamado de Cthulhu". O fandom, por meio de sua capacidade de interpretação e apropriação de conteúdo descrita por Jenkins (1992) e outros teóricos dos estudos de fãs, trouxe significados completamente novos à história pensada por Lovecraft. Este movimento somente foi possível por conta do ambiente da cibercultura, que possibilitou a união de indivíduos em redes que ultrapassam as barreiras geográficas. A página Cthulhu, no Facebook, é um exemplo disso. Com milhares de fãs, é a manifestação da união e o resultado da produção de diversos indivíduos, que se reúnem neste espaço para se tornarem os novos "cultistas" que Lovecraft cita em seu conto.

Diferentemente da história original, esses "cultistas" não são mais apenas um grupo mestiço clandestino que realiza rituais em 
florestas. São pessoas de diversas nacionalidades, unidos pelo apreço que tem pelo autor, pelo conto e pela criatura ancestral Cthulhu. O despertar do monstro na cibercultura se dá por meio de uma caótica mistura de memes, figuras da cultura pop, moda, política e humor. Os elementos contemporâneos se mesclam aos significados originais onde, conforme foi possível perceber, o foco central é o personagem tentacular. Apesar de haver mudanças na forma com a qual os fãs percebem o monstro, suas características mais icônicas permanecem. Enquanto isso, personagens humanos que eram plenamente marcados pela época e pelo ideário lovecraftiano, foram apagados. A prática de textual poaching é evidente: há uma rica interpretação realizada pelos indivíduos, que resultam em imagens e histórias novas.

Os fãs realizam essa atividade facilmente, inserindo o monstro Cthulhu nos contextos mais variados. Basta perceber que o monstro pode ser uma heroína mágica, uma estampa de suéter de Natal, uma fantasia no estilo steampunk, um símbolo político, e um aficionado por tecnologia. Sua imagem, nesses casos, foi completamente dissociada daquele "Deus Antigo", aterrorizante, e passou a ser um personagem carismático, divertido, ou um símbolo político. Ou seja: ele se tornou uma figura capaz de ser moldada pelos fãs de acordo com o que eles desejam e gostam. Isso também reforça a ideia de que um indivíduo é capaz de transitar por diferentes fandoms, e tal fato complexifica as interpretações da história original. Apesar de tudo, no espaço analisado, as pessoas estão unidas por um propósito em comum: todos são fãs de Cthulhu. Apropriando-se da frase do personagem de "O Chamado de Cthulhu", Francis Thurston, esses fãs, que foram atraídos pelo horror cósmico lovecraftiano sabem demais, e o culto ainda vive. 


\section{REFERÊNCIAS}

BLACKMORE, Susan (1999). The Meme Machine. Oxford: Oxford University Press.

BOYD, Danah; ELLISON, Nicole (2007). "Social Network Sites: Definition, History, and Scholarship". Journal of Computer-Mediated Communication, Indiana, Vol.13. In http://jcmc.indiana.edu/vol13/issue1/boyd.ellison.html. Acesso em 16.Jun.2013.

CASTELLS, Manuel (2001). O poder da identidade. Vol.2, 3.ed. São Paulo: Paz e Terra.

DE CERTEAU, Michel (1998). A invenção do cotidiano: Artes de fazer. 3.ed. Rio de Janeiro: Vozes.

DUITS, Linda; ZWAAN, Koos; REIJNDERS, Stijn (2014). The Ashgate Research Companion to Fan Cultures. Farnham: Ashgate. E-book.

GROSSBERG, Lawrence (1992). "Is there a Fan in the House?: The Affective Sensibility of Fandom". In: LEWIS, Lisa (Orgs.) The Adoring Audience: fan culture and popular media. New York: Routledge.

HADEN, David (2010). Lovecraft in Historical Context: essays. E-book.

HILLS, Matt (2002). Fan Cultures. New York: Routledge.

HOLSTI, O. R. (1969). Content Analysis for the Social Sciences and Humanities. Reading: Addison-Wesley.

JENKINS, Henry (2015). Invasores do Texto. 1.ed. Nova Iguaçu: Marsupial. (1992). Textual Poachers: Television Fans and Participatory Culture.

Routledge.

JENSON, Joli (1992). "Fandom as Pathology: The Consequences of Characterization". In: LEWIS, Lisa (Orgs.) The Adoring Audience: fan culture and popular media. New York: Routledge.

JOHN, Fiske (1992). "The Cultural Economy of Fandom". In: LEWIS, Lisa (Orgs.) The Adoring Audience: fan culture and popular media. New York: Routledge.

JOSHI, Sunand Tryambak (2008). The Rise and Fall of the Cthulhu Mythos. Poplar Bluff: Mythos Books LLC.

LEMOS, André (1996). "As estruturas antropológicas do ciberespaço". Textos de 
Cultura e Comunicação. Salvador, n. 35, p.12-27, Julho.

LÉVY, Pierre (1999). Cibercultura. São Paulo: Editora 34.

LOVECRAFT, Howard Phillips (2011). Histórias de Horror: O mito de Cthulhu. Lenita R. Esteves (Trad.). São Paulo: Martin Claret.

MAY, Tim (2004). Pesquisa Social: questões, métodos e processos. 3.ed. Porto Alegre: Artmed.

PHILLIPS, B. S. (1974) Pesquisa Social. Rio de Janeiro: Agir.

RECUERO, Raquel (2009). Redes sociais na internet. 1.ed. Porto Alegre: Editora Meridional.

TYSON, Donald (2010). The Dream World of H.P. Lovecraft: his life, his demons, his universe. 1.ed. Woodbury: Llewellyn Publications. E-book.

(Footnotes)

1 Disponível em: https://www.facebook.com/NyarlathotepCometh. Acesso em: 21.Fev.2017.

2 Disponível em: https://www.facebook.com/pages/Shub-Niggurath/34084202157. Acesso em: 21.Fev.2017.

3 Disponível em: https://www.facebook.com/CoolYogsothoth. Acesso em: 21.Fev. 2017.

4 Disponível em: https://www.facebook.com/pages/The-Shoggoth-Assembly /108860862470296. Acesso em: 21.Fev.2017. 